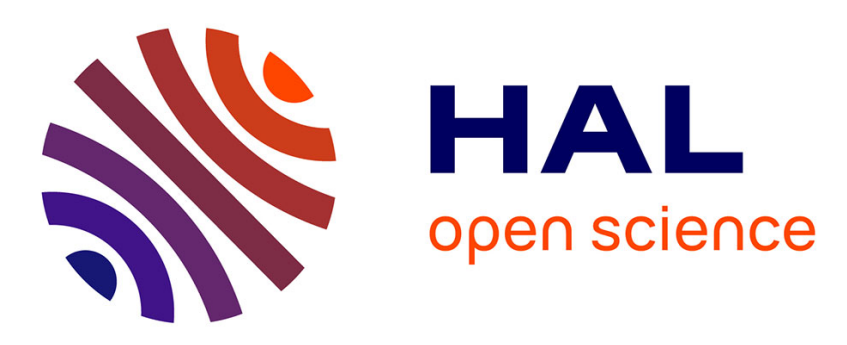

\title{
Robust design of a passive wind turbine system
}

Duc-Hoan Tran, Bruno Sareni, Xavier Roboam, Eric Bru, André de Andrade

\section{- To cite this version:}

Duc-Hoan Tran, Bruno Sareni, Xavier Roboam, Eric Bru, André de Andrade. Robust design of a passive wind turbine system. COMPEL: The International Journal for Computation and Mathematics in Electrical and Electronic Engineering, 2012, vol. 31, pp.932-944. 10.1108/03321641211209816. hal-00762261

\section{HAL Id: hal-00762261 \\ https://hal.science/hal-00762261}

Submitted on 15 Mar 2013

HAL is a multi-disciplinary open access archive for the deposit and dissemination of scientific research documents, whether they are published or not. The documents may come from teaching and research institutions in France or abroad, or from public or private research centers.
L'archive ouverte pluridisciplinaire HAL, est destinée au dépôt et à la diffusion de documents scientifiques de niveau recherche, publiés ou non, émanant des établissements d'enseignement et de recherche français ou étrangers, des laboratoires publics ou privés. 


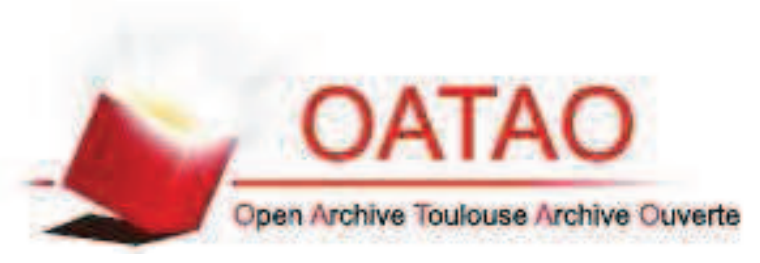

\section{Open Archive TOULOUSE Archive Ouverte (OATAO)}

OATAO is an open access repository that collects the work of Toulouse researchers and makes it freely available over the web where possible.

This is an author-deposited version published in : http://oatao.univ-toulouse.fr/ Eprints ID : 7942

To link to this article : DOI: $10.1108 / 03321641211209816$

URL : http://dx.doi.org/10.1108/03321641211209816

To cite this version :

Tran, Duc Hoan and Sareni, Bruno and Roboam, Xavier and Bru, Eric and Andrade, André De Robust design of a passive wind turbine system. (2012) COMPEL: The International Journal for Computation and Mathematics in Electrical and Electronic Engineering, vol. 31 ( $\mathrm{n}^{\circ} 3$ ). pp. 932-944. ISSN 0332-1649

Any correspondence concerning this service should be sent to the repository administrator: staff-oatao@listes.diff.inp-toulouse.fr 


\title{
Robust design of a passive wind turbine system
}

\author{
Duc Hoan Tran, Bruno Sareni, Xavier Roboam, Eric Bru and \\ André De Andrade \\ LAPLACE UMR CNRS-INPT-UPS, Université de Toulouse, Toulouse, France
}

\begin{abstract}
Purpose - The effectiveness of full passive wind turbine (WT) systems has been recently demonstrated. Such low cost and reliable structures without active control and with a minimum number of sensors can be efficient only if the system design parameters are mutually adapted through an integrated optimal design approach. The purpose of this paper is to analyze the effectiveness of a passive WT with regard to the variations of PMSG electrical parameters.

Design/methodology/approach - This work is more specifically devoted to the sensitivity analysis of a passive WT system according to the electrical variable variations of a Permanent Magnet Synchronous Generator (PMSG). It also investigates the interest of a robust design approach for reducing the sensitivity of the WT efficiency to the most influencing variables.
\end{abstract}

Findings - It is shown that efficiency of the passive WT system is rather sensitive to the variation of the stator flux and DC voltage at the system output.

Originality/value - A robust design approach is investigated in order to reduce the passive WT sensitivity to the stator flux and DC voltage variations.

Keywords Wind power, Turbines, Optimum design, Integrated optimal design,

Multiobjective optimization, Robust design, Sensitivity analysis, Wind turbine

Paper type Research paper

\section{Introduction}

The effectiveness of full passive wind turbine (WT) system without active control unit (Figure 1) has been recently shown in Abdelli et al. (2007), Matt et al. (2008), Sareni et al. (2009) and Tran et al. (2010). For such device, a "natural" impedance adaptation can be achieved with the passive structure by optimizing the accordance between system parameters using an integrated optimal design (IOD) approach based on multiobjective genetic algorithms. The resulting optimization problem consists in maximizing the wind power extraction and minimizing the global system losses for a given wind speed profile while reducing the weight of the WT generator. This approach has been successfully applied in simulation for a 300 W Savonius WT (Abdelli et al., 2007) and experimentally verified on a 1,500 W three-bladed WT (Tran et al., 2010). This paper is devoted more specifically to the sensitivity analysis of the passive WT system. It has been shown that the system efficiency, particularly the quality of the wind power extraction, strongly depends on the electrical parameters of the permanent magnet synchronous generator (PMSG). Even if the actual prototype behavior is in accordance with the design models, it is well known that PMSG electrical variables can vary according to operating conditions (e.g. temperature, load). Furthermore, some differences may occur between sizing parameters obtained from the IOD process and dimensions actually obtained after the prototype building. Therefore, this work aims at quantifying more carefully the variation of the WT efficiency with regard to some possible variations of these electrical variables. 
The remainder of the paper is organized as follows. Section 2 describes the IOD process used for optimizing passive WT systems. In Section 3, the main characteristics of a PMSG prototype devoted to a three-bladed WT are presented. In Section 4, the sensitivity analysis of this prototype is performed with regard to PMSG electrical variable variations. A robust design approach is investigated in Section 5 in order to reduce the sensitivity of the WT system to the most influent factors that can affect the WT efficiency. Finally, conclusions are drawn in Section 6.

\section{IOD of passive WT systems}

In earlier studies, the interest of passive WTs has been demonstrated. Such systems without active control unit and with a minimum of sensors are particularly reliable and can be efficient only if a good accordance between PMSG parameters and WT features can be found. To achieve this objective, an IOD process based on multiobjective genetic algorithms has been developed. It consists in determining the optimal PMSG characteristics for a particular WT from the best tradeoffs which minimize the total system mass and maximize the average WT useful power during a reference wind cycle (Figure 2).

\subsection{Model of the WT system}

All design and behavioral models of the passive WT have been developed in Abdelli et al. (2007), Sareni et al. (2009) and Tran et al. (2010):

- Wind model. A typical wind cycle defined in terms of speed harmonic decomposition is taken for describing the wind speed behavior $V_{w}$ :

$V_{w}(t)=10+0.2 \sin (0.1047 t)+2 \sin (0.2665 t)+\sin (1.2930 t)+0.2 \sin (3.6645 t)$

- WT model. A three-bladed WT of radius $R_{w}$ is considered in this study. It provides a wind power $P_{w}$ defined by:

$$
P_{w}=\frac{1}{2} C_{p}(\lambda) \rho \pi R_{w}^{2} V_{w}^{3}
$$

where $\rho$ denotes the air density. The $C_{p}$ power coefficient varies as a function of the tip speed ratio $\lambda=R_{w} \Omega_{w} / V_{w}$. For the Bergey XL.1 three-bladed WT, it can be interpolated by a seventh order polynomial (Tran et al., 2010):

$$
C_{p}(\lambda)=\sum_{k=0}^{7} a_{k} \lambda^{k}
$$

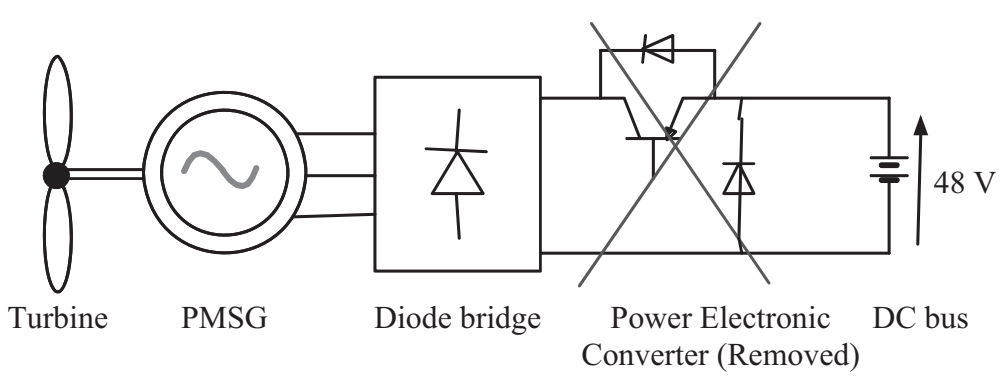

Figure 1. 
Figure 2.

IOD process based on multiobjective optimization

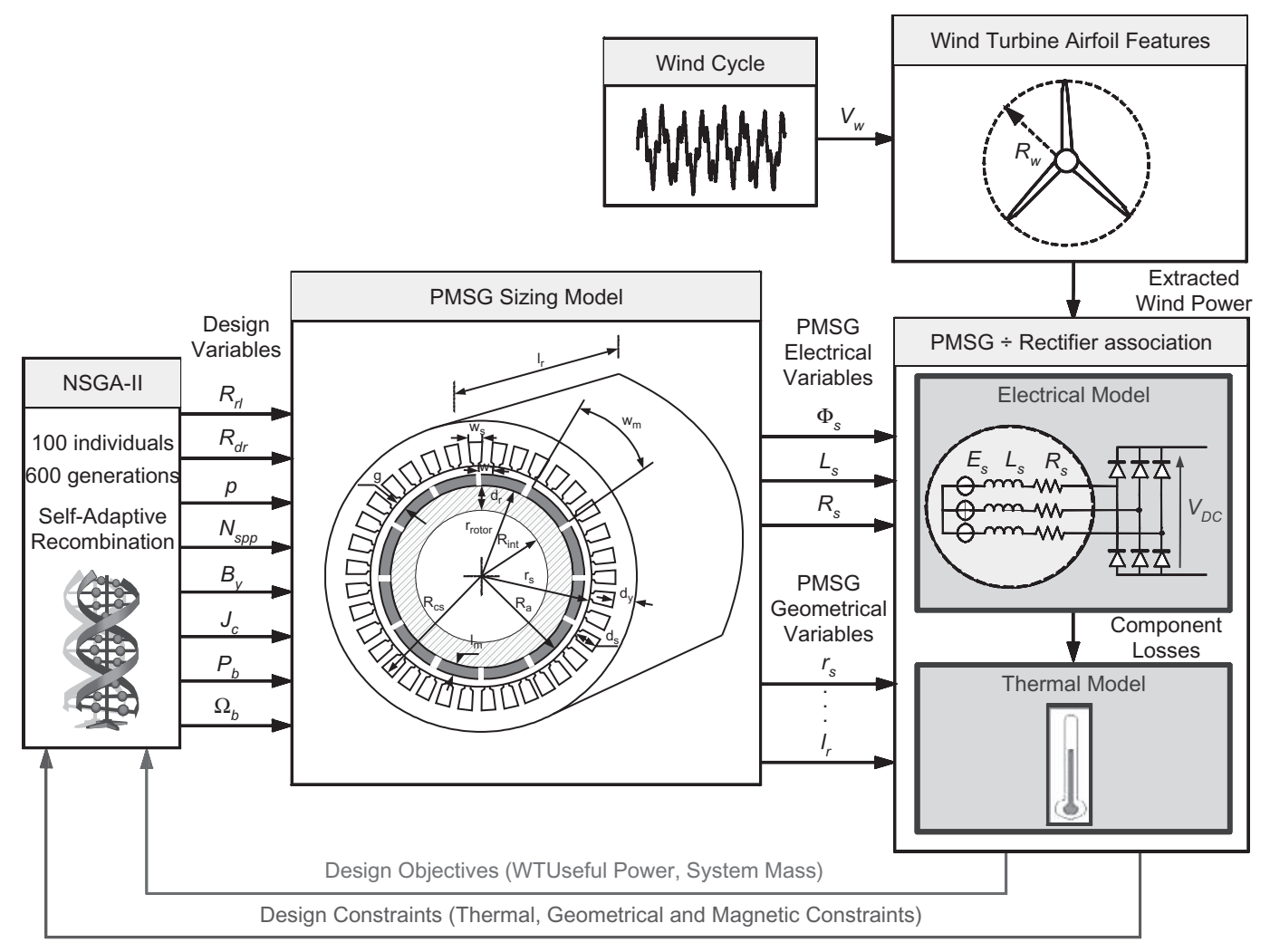

where the interpolation factors are $a_{7}=-3.9 \times 10^{-8}, a_{6}=-4.2 \times 10^{-6}$, $a_{5}=2.1 \times 10^{-4}, a_{4}=-3.1 \times 10^{-3}, a_{3}=1.6 \times 10^{-2}, a_{2}=-1.8 \times 10^{-2}$, $a_{1}=1.7 \times 10^{-2}$ and $a_{0}=-1.9 \times 10^{-3}$.

- PMSG sizing model. An analytical sizing model allows us to extract all electrical and geometrical parameters from the chosen design variables (these variables are stated in the following). For reason of complexity and space limitation, this model is not explained in detail in the paper. We invite readers to refer to Sareni et al. (2009) and Tran et al. (2010) for more information.

- PMSG-rectifier association. In order to reduce the computing time of temporal simulation a simplified DC equivalent model (called mixed-reduced model in Sareni et al. (2009)) has been proposed for representing the PMSG-diode rectifier association. This model includes the armature reaction in the generator and the diode overlapping during the commutation interval.

\subsection{Design variables}

Design variables and their associated bounds are given in Table I. These variables should be optimized in the IOD process in accordance with the design objectives defined in the next subsection.

\subsection{Design objectives}

The first objective $O F_{1}$ resides in the maximization of the average useful power $P_{u}$ during the wind cycle defined in equation (1). This power consists of the wind power 
extracted from the WT $P_{w}$ reduced from all losses in the system. These losses include mechanical losses $P_{m}$ in the turbine, conduction losses $P_{c}$ in the diode rectifier, iron losses $P_{i}$ and Joule losses $P_{j}$ in the PMSG. For more details about the calculation of these losses, we invite readers to refer to Sareni et al. (2009):

$$
O F_{1}=\max \left\{P_{u}\right\}=\max \left\{P_{w}-P_{m}-P_{j}-P_{i}-P_{c}\right\}
$$

It should be noted that maximizing the useful power implies the maximization of the extracted wind power as well as the minimization of all losses in the system. The second objective $\mathrm{OF}_{2}$ consists in the minimization of the total system mass $M_{\text {tot }}$ which includes the WT mass $M_{W T}$, the PMSG mass $M_{P M S G}$ and the radiator mass $M_{\text {rad }}$ associated with the diode rectifier:

$$
O F_{2}=\min \left\{M_{t o t}\right\}=\min \left\{M_{W T}+P_{P M S G}+M_{r a d}\right\}
$$

The PMSG mass $M_{P M S G}$ is evaluated from the mass of each component (iron, copper and magnet) and from the PMSG geometric features (Tran et al., 2010). A constant value of $34 \mathrm{~kg}$ is taken for the WT mass.

\subsection{Design constraints}

Five constraints are included to ensure the system feasibility with regard to design variable variations in the IOD process. These constraints concern the number of conductors per slot (higher than one and limited by the minimal section of winding conductors), the maximum temperature associated with the copper windings in the PMSG, the demagnetization limit of the magnets and the maximum temperature in the semiconductor junctions of the diode rectifier. All details about the calculation of these constraints and the computation of thermal values in the PMSG and in the diode rectifier can be found in Sareni et al. (2009).

\subsection{NSGA-II tuning}

The non-dominated sorting genetic algorithm (NSGA-II) (Deb, 2001) with self-adaptive recombination (Sareni et al., 2004) is used for the WT optimization. The crossover and mutation probabilities are $p_{c}=1$ and $p_{m}=0.1$. The population and archive sizes are set to 100 and the generation number is $G=600$. Five independent runs are made to

\begin{tabular}{|c|c|c|c|}
\hline Design variable & Nature & Bounds & \\
\hline Radius Length Ratio & Continuous & $R_{r l} \in[0.1,5]$ & \\
\hline Slot Depth/Radius Ratio & Continuous & $R_{d r} \in[0.03,0.3]$ & \\
\hline Number of Slots per Pole Per Phase & Discrete & $N_{s p p} \in\{1, \ldots, 5\}$ & \\
\hline Number of Pole Pairs & Discrete & $p \in\{1, \ldots, 30\}$ & \\
\hline Current Density $\left(\mathrm{A} \mathrm{mm}^{-2}\right)$ & Continuous & $J_{c} \in[0.5,4]$ & Table I. \\
\hline Yoke Induction $(\mathrm{T})$ & Continuous & $B_{y} \in[1.2,1.9]$ & Design variables used \\
\hline Base Power (W) & Continuous & $P_{b} \in[300,3000]$ & for the passive WT \\
\hline Base Speed (rad. s ${ }^{-1}$ ) & Continuous & $\Omega_{b} \in[25,95]$ & optimization \\
\hline
\end{tabular}
take into account of the NSGA-II stochastic feature. 
Figure 3.

Optimal PMSG prototype resulting from the IOD process

\section{PMSG prototype for a $1,500 \mathrm{~W}$ three-bladed WT}

A PMSG prototype for a $1,500 \mathrm{~W}$ three-bladed WT has been obtained from the previous IOD process (Figure 3 ). This prototype has been experimentally validated in Tran et al. (2010).

The efficiency of the passive WT system (especially the wind power extraction) strongly depends on the electrical parameters of the PMSG, with respect to the WT power coefficient. Therefore, the values of these parameters issued from the IOD process are compared in Table II with those of the actual prototype. Even if there is a good agreement between the prototype and the corresponding design models, it is well known that these electrical parameters can vary according to the operating conditions and the WT system environment. Moreover, the DC bus voltage (and consequently the PMSG stator voltage) also depends on the battery state of charge, varying from 42 to $53 \mathrm{~V}$. All variations of these factors can modify the WT system efficiency which justifies the sensitivity analysis investigated in the next section. We will particularly examine the influence of the stator flux $\Phi_{s}$, the stator resistance $R_{s}$, the stator inductance $L_{s}$ and the $\mathrm{DC}$ voltage $V_{D C}$ on the WT efficiency. It should be noted that the stator flux is chosen instead of the magnetic flux density because it directly sets the emf value and can then be easily measured on the actual prototype. Note that we do not investigate the WT efficiency according to wind conditions. This work has been already done in Roboam et al. (2008) for a Savonius WT.

\section{Sensitivity analysis of the actual optimal prototype}

\subsection{Sensitivity indices}

The sensitivity analysis is carried out using two sensitivity indices which measure the effect of varying factors on the WT efficiency. The first sensitivity criterion is the "useful power loss" index defined as follows:

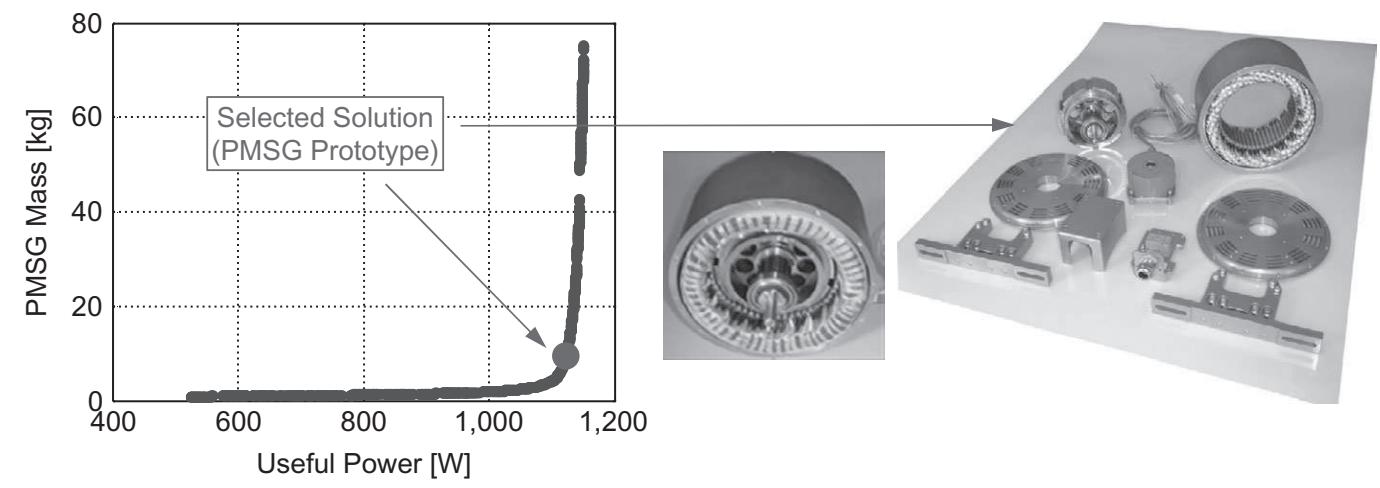

Table II.

Electrical parameters of the optimal PMSG

\begin{tabular}{lccc}
\hline PMSG & $\begin{array}{c}\text { Stator flux } \\
\Phi_{s}^{*}(\mathrm{~Wb})\end{array}$ & $\begin{array}{c}\text { Stator resistance } \\
R_{s}^{*}(\Omega)\end{array}$ & $\begin{array}{c}\text { Stator inductance } \\
L_{s}^{*}(\mathrm{mH})\end{array}$ \\
\hline Analytical model & 0.21 & 0.13 & 1.37 \\
Finite elements & 0.21 & 0.13 & 1.40 \\
Measurements (actual prototype) & 0.20 & 0.14 & 1.42 \\
\hline
\end{tabular}




$$
\Delta P_{u}(\mathbf{x})=\frac{P_{u}(\mathbf{x})-\min _{V(\mathbf{x})} P_{u}}{P_{u}(\mathbf{x})}
$$

where $\mathbf{x}$ denotes the design variables of the actual PMSG prototype, $P_{u}(\mathrm{x})$ is the useful power for the variable positioning on $\mathrm{x}$ and $V(\mathbf{x})$ is a neighborhood representing the uncertainty domain associated with the varying factors $\left(\Phi_{s}, R_{s}, L_{s}\right.$ and $\left.V_{D C}\right)$.

The second sensitivity index is the target signal-to-noise ratio of Taguchi (Taguchi et al., 2004) defined as follows:

$$
S N_{T}=10 \log _{10}\left(\frac{\mu_{P_{u}}}{\sigma_{P_{u}}}\right)^{2}
$$

where $\mu_{P_{u}}$ denotes the mean of the useful power on the uncertainty domain and $\sigma_{P_{u}}$ is the corresponding standard deviation.

The use of these two indices has been preferred to traditional sensitivity function methods based on derivatives with respect to the varying factor. Such methods, evaluating the sensitivity in a single point of the uncertainty domain, are exclusively "local" (Frey and Patil, 2002) and are not able to include multidimensional averaging (i.e. estimate the effect of a factor while others are varying as well). The useful power loss index and the target signal-to-noise ratio are better suited, by giving "global" sensitivity information on the overall neighborhood. Large values of the signal-to-noise ratio and small values of the useful power loss index indicate a good robustness with regard to the varying factors.

\subsection{Effect of one varying factor}

We first analyze the effect of a variation of each factor independently, the other factors being unchanged at their reference value (i.e. the value of the actual PMSG prototype). Each varying factor $x$ is submitted to a positive and a negative variation $\Delta x$. The magnitude of the variation is set to 10 percent of the corresponding reference value $\left(\Delta x=10\right.$ percent $x$ ). Consequently, a 1D neighborhood, defined by the three points $x^{*}$, $x^{*}-\Delta x$ and $x^{*}+\Delta x$, is used for the sensitivity indices computation. Table III put forward the values of the sensitivity indices for each investigated factor. Worst values of the sensitivity indices are indicated in italics types. It can be seen from this table that the WT efficiency is not affected by $R_{s}$ and $L_{s}$ variations but is sensitive to $\Phi_{s}$ and $V_{D C}$ deviations from their standard values (respectively $0.21 \mathrm{~Wb}$ and $48 \mathrm{~V}$ ). This result is not surprising since the DC voltage and the stator flux are directly coupled with the WT rotational speed which conditions the wind power extraction. The effect of each varying factor on the load characteristic in the wind power - rotational speed plan is shown in Figure 4. The PMSG and WT characteristics are compared on this figure for wind speeds varying from 8 to $14 \mathrm{~m} \mathrm{~s}^{-1}$. A dashed curve corresponding to an "ideal"

\begin{tabular}{lcccc}
\hline PMSG & $\begin{array}{c}\text { Stator resistance } \\
R_{s}\end{array}$ & $\begin{array}{c}\text { Stator inductance } \\
L_{s}\end{array}$ & $\begin{array}{c}\text { Stator flux } \\
\Phi_{s}\end{array}$ & $\begin{array}{c}\text { DC voltage } \\
V_{D C}\end{array}$ \\
\hline $\begin{array}{l}\text { Signal-to-noise ratio } S N_{T}(\mathrm{~dB}) \\
\begin{array}{l}\text { Useful power loss index } \Delta P_{u} \\
(\%)\end{array}\end{array}$ & 39.1 & 57.7 & 25.2 & 35.5 \\
& 1.1 & 0.2 & 8.8 & 3.3
\end{tabular}

Table III.

Effect of the PMSG electrical parameter variations quantified with two sensitivity indices 


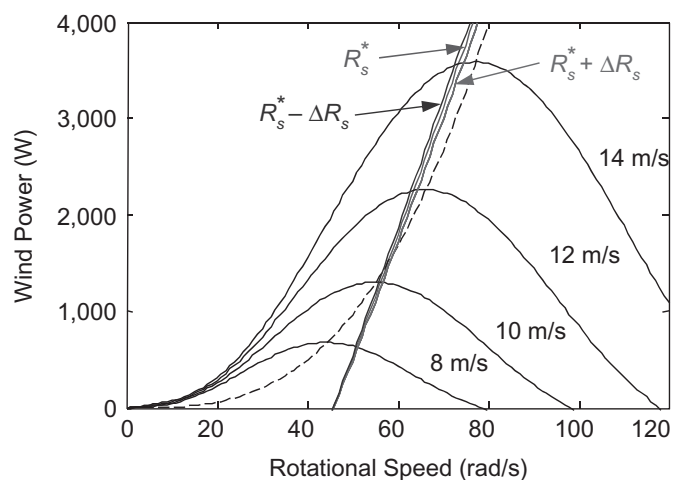

(a) Stator resistance Rs

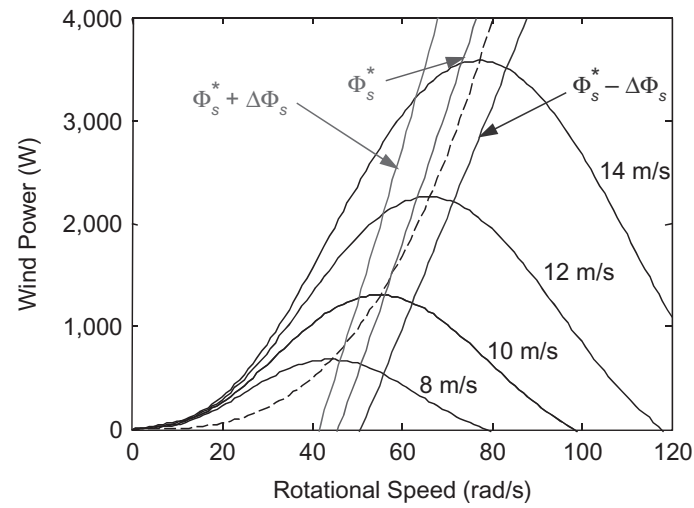

(c) Magnetic Flux $\Phi_{s}$

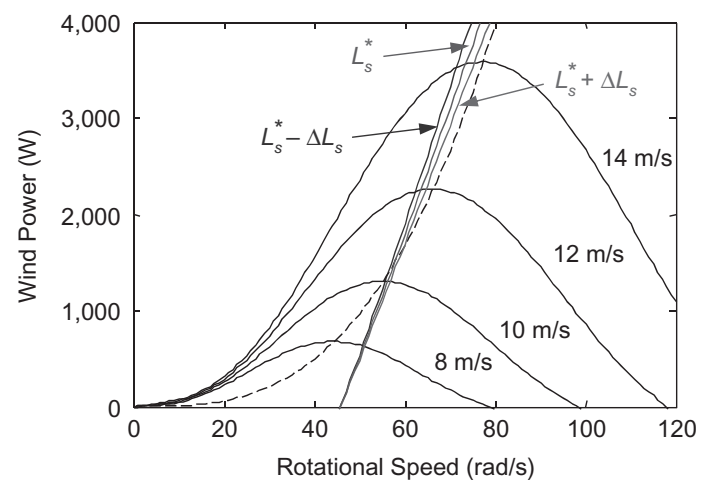

(b) Stator inductance Ls

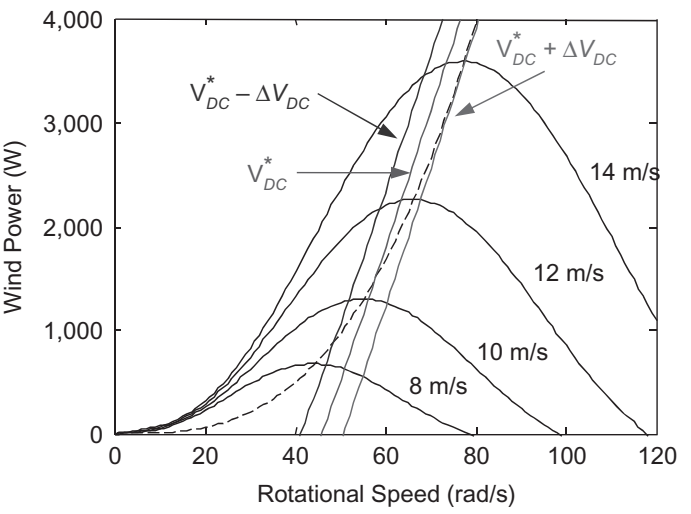

(d) DC voltage VDC electrical parameter variations on the wind power extraction
Notes: (a) Stator resistance $\mathrm{R}_{\mathrm{s}}$; (b) stator inductance $\mathrm{L}_{\mathrm{s}}$; (c) magnetic flux $\Phi_{\mathrm{s}}$; (d) DC voltage $\mathrm{V}_{\mathrm{DC}}$

wind power extraction is also plotted. It should be noted that the PMSG prototype has been optimized in compliance with the reference wind cycle defined in equation (2) which approximately varies from 7 to $13 \mathrm{~ms}^{-1}$. Consequently, the optimal PMSG characteristic is very close to the ideal wind extraction curve in this wind speed range. The same conclusions can be drawn from this figure concerning the WT sensitivity to PMSG electrical parameters. The wind power extraction is particularly sensitive to $\Phi_{s}$ and $V_{D C}$ variations but rather robust with regard to $R_{S}$ and $L_{s}$ variations.

\subsection{Effect of two varying factors}

Considering that the $\mathrm{DC}$ voltage and the stator flux are the most influent factors, we now investigate the effect of combined variations of these parameters on the WT efficiency. For that purpose, a 2D neighborhood consisting in nine different points (including the reference point no. 1), is taken for the uncertainty domain (Figure 5). The magnitude of the variations is set to 10 percent of the corresponding reference value. Such combined modifications of two factors may have cumulative or compensating effects with regard to the damage of the WT efficiency. We give in Table IV the sensitivity indices computed with this $2 \mathrm{D}$ neighborhood. It can be seen from this table that the useful power loss index is double in comparison with the previous case (i.e. the one varying factor case) which indicates some possible cumulative effect of DC voltage and stator flux variations 


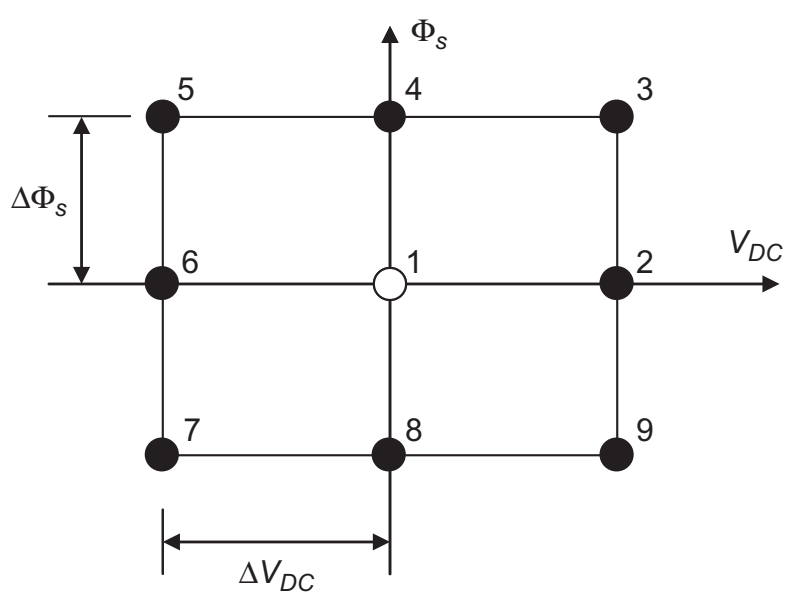

Note: The central point represents the reference point

Sensitivity index

Useful power loss index $\Delta P_{u}(\%)$

Signal-to-noise ratio $S N_{T}(\mathrm{~dB})$
Figure 5.

2D neighborhood defining the uncertainty domain of $\Phi_{S}$ and $V_{D C}$ variables

Table IV.

Value

16.2

24.4
Effect on DC voltage and stator flux variations quantified with two sensitivity indices

on the WT efficiency. However, the signal-to-noise ratio is quite similar to the worst value of Table III, which points out a rather good robustness with regard to combined variations of $\Phi_{s}$ and $V_{D C}$.

We finally examine the sensitivity of the overall Pareto-optimal front of Figure 3 by considering three effective objective functions (Branke, 1998) taking into account the WT robustness. These functions are defined as follows:

$$
\begin{aligned}
& \tilde{P}_{u}^{\min }(\mathbf{x})=\min _{i=1 \ldots 9} P_{u}(\mathbf{x}) \\
& \tilde{P}_{u}^{\text {mean }}(\mathbf{x})=\operatorname{mean}_{i=1 \ldots 9} P_{u}(\mathbf{x}) \\
& \tilde{P}_{u}^{\max }(\mathbf{x})=\max _{i=1 \ldots 9} P_{u}(\mathbf{x})
\end{aligned}
$$

where $i$ denotes a point of the 2D neighborhood shown in Figure 5. The comparison of these functions on the original Pareto-optimal front is shown in Figure 6.

It should be underlined that no additional optimization has been performed in this section which is strictly dedicated to sensitivity analysis. In fact, the objective function related to the useful power $P_{u}$ is recalculated from each sizing vector $\mathbf{x}^{*}$ extracted from the initial Pareto-front by applying the calculation of effective functions derived from equations (8) to (10).

Figure 6 shows the significant deviation of the Pareto-optimal front in the worst case (i.e. $\widetilde{P}_{u}^{\min }\left(\mathbf{x}^{*}\right)$ ) resulting from the combined effect of the factors on the WT efficiency. 


\section{Figure 6.}

Sensitivity of the Pareto-optimal front to $\mathrm{DC}$ voltage and stator flux variations

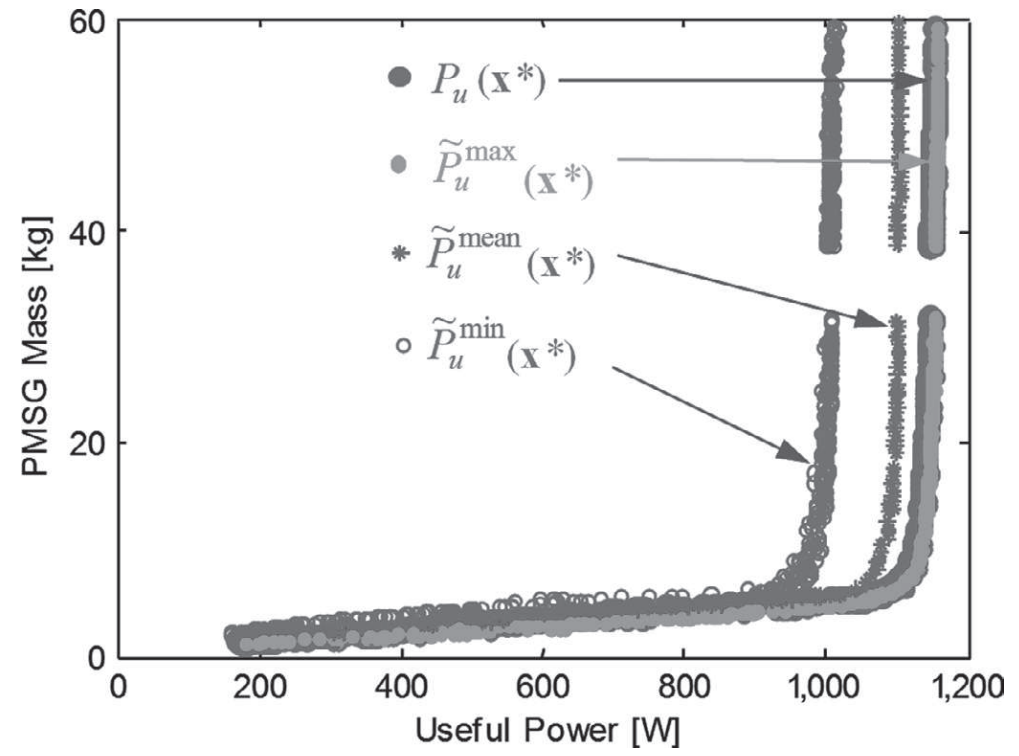

Nevertheless, the average deviation represented by the $\tilde{P}_{u}^{\text {mean }}\left(\mathbf{x}^{*}\right)$ function, is not so high. The conclusions are similar to that drawn from the analysis of sensitivity indices. Finally, it can be seen from Figure 6 that the best case (i.e. $\left.\tilde{P}_{u}^{\max }\left(\mathbf{x}^{*}\right)\right)$ coincides with the original front (i.e. the reference non-perturbed case $\left.P_{u}\left(\mathbf{x}^{*}\right)\right)$. This means that there is no possible improvement of the WT efficiency due to $\Phi_{s}$ and $V_{D C}$ variations. This also indicates a good convergence of the optimization process used for improving the WT efficiency.

\section{Robust design of the passive WT system}

In order to reduce the sensitivity of the WT efficiency to $\Phi_{s}$ and $V_{D C}$ variations, a robust design methodology is investigated. More details about robust design methods can be found in Trosset (1996), Branke (1998), Lee and Park (2001), Deb and Gupta (2006), Steiner et al. (2004) and Cioffi et al. (2006). Contrarily to the previous section, several optimizations with different objective functions are performed: our approach consists in maximizing the effective objective functions $\tilde{P}_{u}^{\text {min }}, \tilde{P}_{u}^{\text {mean }}$ defined by equations (8) and (9) instead of the WT useful power $\left(P_{u}\right)$ during the reference wind cycle. The rate of $\Phi_{s}$ and $V_{D C}$ variations is the same as previously (i.e. 10 percent). The NSGA-II is used for optimizing the system mass and each effective function associated with the WT useful power. It should be noted that the computation time of the effective objective functions is increased according to the number of explorations in the neighborhood of a given solution. Consequently, the CPU time for solving the "robust problem" (with $\tilde{P}_{u}^{\text {min }}$ or $\tilde{P}_{u}^{\text {mean }}$ ) is increased by 9 with the 2 D neighborhood of Figure 5 in comparison with a traditional approach without robust formulation (with $P_{u}$ ). In order to clarify the analysis, we define as $\mathbf{x}^{*}, \mathbf{x}_{\text {min }}^{*}, \mathbf{x}_{\text {mean }}^{*}$, the set of design variables relative to Pareto-optimal configurations obtained from each multiobjective optimization, i.e. by, respectively, maximizing as objective function $P_{u}, \tilde{P}_{u}^{\min }, \tilde{P}_{u}^{\operatorname{mean}}$ while minimizing the WT system mass. 
By zooming on the best tradeoffs in the "elbow" zone, the original Pareto-front (i.e. $\left.P_{u}\left(\mathbf{x}^{*}\right)\right)$ obtained in Section 3 is compared in Figure 7 with the Pareto-optimal solutions issued from each effective objective function optimization (i.e. $P_{u}\left(\mathbf{x}_{\min }^{*}\right)$ and $P_{u}\left(\mathbf{x}_{\text {mean }}^{*}\right)$ ). It can be seen that the useful power of the robust solutions $\mathbf{x}_{\text {min }}^{*}$ and $\mathbf{x}_{\text {mean }}^{*}$ is slightly degraded but remain quite close to the original solutions (without robust formulation). On the other hand, in order to validate the effectiveness of the robust approach, the sensitivity of the robust solutions is examined.

For that purpose, Figure 8 shows (in green) in the objective space the set of solutions obtained with the original sizing when the useful power ((i.e. $\left.P_{u}\left(\mathbf{x}^{*}\right)\right)$ and the associated

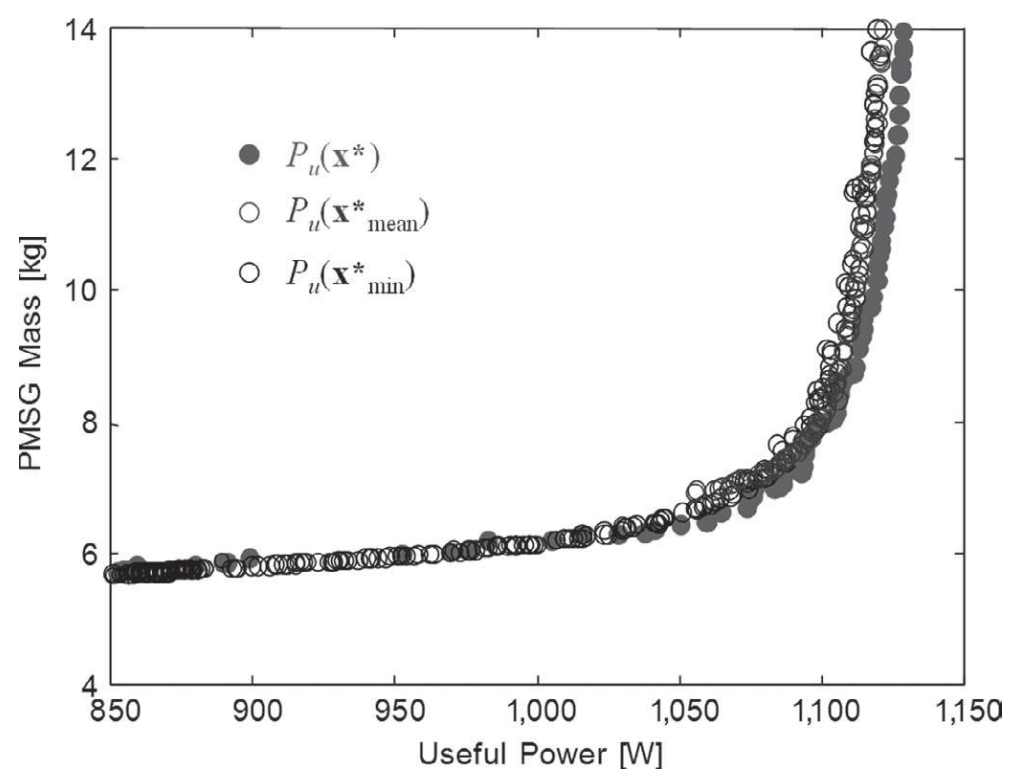

Figure 7.

Useful powers of robust sizing solutions $\left(\mathbf{x}_{\text {min }}^{*}\right.$ and $\left.\mathbf{x}_{\text {mean }}^{*}\right)$ compared with the original sizing solutions $\mathbf{x}^{*}$

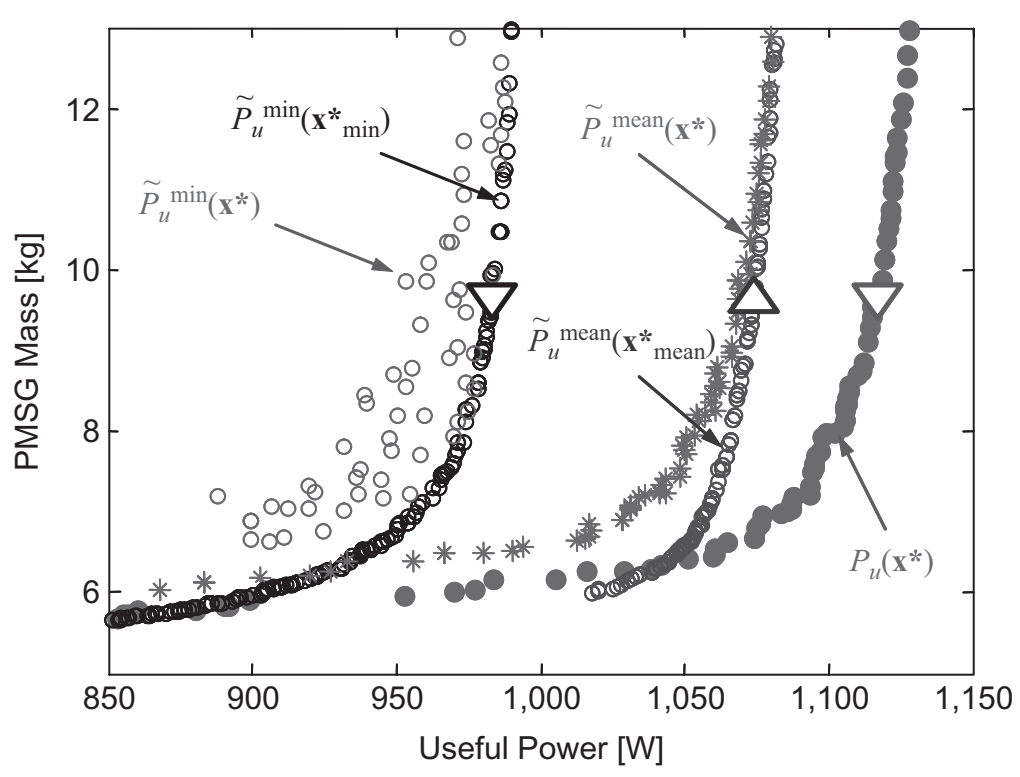

Figure 8.

Comparison of useful powers $P_{u}$ and associated effective objective functions $\left(\tilde{P}_{u}^{\min }\right.$ and $\tilde{P}_{u}^{\text {mean }}$ ) of the original sizing solutions $\mathbf{x}^{*}$ with robust sizing solutions $\left(\mathbf{x}_{\text {min }}^{*}\right.$ and $\left.\mathbf{x}_{\text {mean }}^{*}\right)$ 
effective functions (i.e. $\tilde{P}_{u}^{\text {min }}\left(\mathbf{x}^{*}\right)$ and $\left.\tilde{P}_{u}^{\text {mean }}\left(\mathbf{x}^{*}\right)\right)$ are calculated. For ${ }_{*}$ comparison, we also plot the Pareto-optimal fronts of the robust solutions $\left(\mathbf{x}_{\min }^{*}\right.$ and $\left.\mathbf{x}_{\text {mean }}^{*}\right)$, respectively, obtained from the optimizations of the corresponding effective objective functions (i.e. $\tilde{P}_{u}^{\text {min }}\left(\mathbf{x}_{\text {min }}^{*}\right)$ in black and $\widetilde{P}_{u}^{\text {mean }}\left(\mathbf{x}_{\text {mean }}^{*}\right)$ in blue). It can be verified that the robust optimization approach slightly reduces the sensitivity to $\Phi_{s}$ and $V_{D C}$ variations without damaging the WT efficiency (as previously shown in Figure 7). Indeed, this figure shows that both Pareto-optimal fronts $\tilde{P}_{u}^{\min }\left(\mathbf{x}_{\text {min }}^{*}\right)$ and $\tilde{P}_{u}^{\text {mean }}\left(\mathbf{x}_{\text {mean }}^{*}\right)$ dominate the corresponding effective objective functions of the original solutions (i.e. $\tilde{P}_{u}^{\min }\left(\mathbf{x}^{*}\right)$ and $\left.\tilde{P}_{u}^{\text {mean }}\left(\mathbf{x}^{*}\right)\right)$. This indicates a good convergence of the optimization process for finding robust Pareto-optimal solutions.

We finally indicate with triangles in Figure 8, three particular sizing solutions with identical PMSG mass of $9.8 \mathrm{~kg}$. It should be noted that the solution lying in the original front represents the reference solution (i.e. the actual PMSG prototype). The design variables associated with these three particular solutions are given in Table V. The corresponding useful power, effective objective functions and sensitivity indices are mentioned in Table VI. In this last table, best values are indicated in italics types.

As expected, it can be seen from Table VI that the sizing solutions optimized in compliance with the effective objective functions are more robust than the reference prototype. For these two solutions, the effective objective functions and sensitivity indices are slightly improved in comparison with the reference prototype. In particular,

Table V.

Design variables relative to three optimal PMSG of $9.8 \mathrm{~kg}$ with different sensitivity features

\begin{tabular}{|c|c|c|c|}
\hline & $\begin{array}{l}\text { Optimal solution } \mathbf{x}^{*}(9.8 \mathrm{~kg}) \\
\text { (reference prototype) }\end{array}$ & $\begin{array}{l}\text { Robust solution } \\
\mathbf{x}_{\text {mean }}^{*}(9.8 \mathrm{~kg})\end{array}$ & $\begin{array}{c}\text { Robust solution } \\
\mathbf{x}_{\min }^{*}(9.8 \mathrm{~kg})\end{array}$ \\
\hline Radius/length ratio $R_{r l}$ & 1.45 & 5 & 3.16 \\
\hline Slot depth/radius ratio $R_{d r}$ & 0.3 & 0.3 & 0.3 \\
\hline Yoke induction $B_{y}[\mathrm{~T}]$ & 1.8 & 1.2 & 1.4 \\
\hline Number of pole pairs $p$ & 3 & 7 & 7 \\
\hline Current density $J_{s}$ & & & \\
\hline$\left[\mathrm{A} \mathrm{mm}^{-2)}\right]$ & 3.97 & 1.61 & 3.63 \\
\hline Sizing power $P_{\operatorname{dim}}(\mathrm{W})$ & 1,753 & 1,232 & 1,860 \\
\hline $\begin{array}{l}\text { No. of slots per pole per } \\
\text { phase } N_{\text {e力n }}\end{array}$ & & & \\
\hline $\begin{array}{l}\text { phase } N_{\text {epp }} \\
\text { Base speed } \Omega_{d i m}\left(\text { rad. s }^{-1}\right)\end{array}$ & $\begin{array}{c}3 \\
76.6\end{array}$ & $\begin{array}{c}1 \\
73.9\end{array}$ & $\begin{array}{c}1 \\
75.8\end{array}$ \\
\hline Stator resistance $R_{S}(\Omega)$ & 0.13 & 0.06 & 0.08 \\
\hline Stator inductance $L_{s}(\mathrm{mH})$ & 1.41 & 0.51 & 0.56 \\
\hline Stator flux $\Phi_{s}(\mathrm{~Wb})$ & 0.21 & 0.09 & 0.09 \\
\hline
\end{tabular}

\section{Table VI.}

Efficiency relative to three optimal PMSG of $9.8 \mathrm{~kg}$ with different sensitivity features

\begin{tabular}{lccc}
\hline & $\begin{array}{c}\text { Optimal solution } \\
\mathbf{x}^{*}(9.8 \mathrm{~kg}) \\
\text { (reference prototype) }\end{array}$ & $\begin{array}{c}\text { Robust solution } \\
\mathbf{x}_{\text {mean }}^{*}(9.8 \mathrm{~kg})\end{array}$ & $\begin{array}{c}\text { Robust solution } \\
\mathbf{x}_{\text {min }}^{*}(9.8 \mathrm{~kg})\end{array}$ \\
\hline$P_{u}(\mathrm{~W})$ & 1,115 & 1,107 & 1,105 \\
$\tilde{P}_{u}^{\operatorname{mean}}(\mathrm{W})$ & 1,044 & 1,074 & 1,064 \\
$\tilde{P}_{u}^{\min }(\mathrm{W})$ & 910 & 970 & 982 \\
$\Delta P_{u}(\%)$ & 16.2 & 12.4 & 10.9 \\
$S N_{T}(\mathrm{~dB})$ & 24.41 & 26.34 & 26.47 \\
\hline
\end{tabular}


the useful power loss index drops from 16.2 to 10.9 percent. However, this value remains rather high indicating that it is not possible to totally desensitize the WT efficiency versus DC voltage and stator flux variations. It can also be noted from Table $\mathrm{V}$ that optimal solutions optimized with regard to the effective objective functions significantly differ from the actual prototype although they have similar characteristics in the objective space. This means that some additional degrees of freedom could probably be exploited in order to improve other performance criteria (e.g. manufacturing cost, ecological impact, mechanical fatigue).

\section{Conclusions}

In this paper, the effectiveness of a passive WT has been analyzed with regard to the variations of PMSG electrical parameters. The sensitivity to these parameters has been quantified using two sensitivity indices: the useful power loss index and the target signal-to-noise ratio of Taguchi. It has been shown that the WT efficiency is rather sensitive to stator flux and DC voltage values. In particular, the quality of the wind power extraction strongly depends on the optimal values of these factors issued from the optimization process. In order to improve the WT robustness, a robust design approach has been investigated, consisting in optimizing effective objective functions related to the WT useful power. These functions are able to take into account the WT efficiency as well as the sensitivity to DC voltage and stator flux variations. Even if the WT robustness has been slightly improved with this approach, results have shown that it is not possible to totally desensitize the WT efficiency to these factor variations. On the other hand, it has been noted from this study that different PMSG configurations in the design variable space can be found with the same features in the objective space and various sensitivity levels. This also suggests that other degrees of freedom are available for optimizing additional performance criteria such as manufacturing costs or ecological impact.

\section{References}

Abdelli, A., Sareni, B. and Roboam, X. (2007), "Optimization of a small passive wind turbine generator with multiobjective genetic algorithms", International Journal of Applied Electromagnetics and Mechanics (IJAEM), Vol. 26 Nos 3/4, pp. 175-82.

Branke, J. (1998), "Creating Robust solutions by means of evolutionary algorithms", Parallel Problem Solving from Nature - PPSN V, Lecture Notes in Computer Sciences, Springer, London, pp. 119-28 (Selected papers).

Cioffi, M., Formisano, A., Martone, R., Steiner, G. and Watzenig, D. (2006), "A fast method for statistical Robust optimization”, IEEE Trans. Magn., Vol. 42 No. 4, pp. 1099-102.

Deb, K. (2001), Multi Objective Optimization Using Evolutionary Evolutionary Algorithms, Wiley Interscience Series in Systems and Optimization, Wiley, Chichester.

Deb, K. and Gupta, H. (2006), "Introducing robustness in multiobjective optimization", Evolutionary Computation, Vol. 14 No. 4, pp. 463-94.

Frey, H.C. and Patil, S.R. (2002), "Identification and review of sensitivity analysis methods", Risk Analysis, Vol. 22 No. 3, pp. 553-78.

Lee, K.H. and Park, G.J. (2001), "Robust optimization considering tolerances of design variables", Computer and Structures, Vol. 79, pp. 77-86. 
Matt, D., Martire, T., Enrici, P., Jac, J. and Ziegler, N. (2008), "Passive wind energy conversion system association of a direct-driven synchronous motor with vernier effect and a diode rectifier", 14th IEEE Mediterranean Electrotechnical Conference (MELECON 2008), Ajaccio (France), pp. 479-83.

Roboam, X., Abdelli, A. and Sareni, B. (2008), "Optimization of a passive small wind turbine based on mixed Weibull-turbulence statistics of wind", Proc. Electrimacs 2008, Québec, Canada.

Sareni, B., Regnier, J. and Roboam, X. (2004), "Recombination and self-adaptation in multi-objective genetic algorithms", 6th International Conference on Artificial Evolution, EA 2003, Marseille, France, Lecture Notes in Computer Sciences, Vol. 2936, Springer, New York, NY, pp. 115-27 (Selected papers).

Sareni, B., Abdelli, A., Roboam, X. and Tran, D.H. (2009), "Model simplification and optimization of a passive wind turbine generator", Renewable Energy, Vol. 4 No. 12, pp. 2640-50.

Steiner, G., Weber, A. and Magele, C. (2004), "Managing uncertainties in electromagnetic design problems with Robust optimization", IEEE Trans. Magn., Vol. 40 No. 2, pp. 1094-9.

Taguchi, G., Chowdhury, S. and Wu, Y. (2004), Taguchi’s Quality Engineering Handbook, Wiley, New York, NY.

Tran, D.H., Sareni, B., Roboam, X. and Espanet, C. (2010), "Integrated optimal design of a passive wind turbine system: an experimental validation", IEEE Transactions on Sustainable Energy, Vol. 1 No. 1, pp. 48-56.

Trosset, M. (1996), "Tagushi and robust optimization”, Tech. Report 96-31, Department of Computational \& Applied Mathematics, Rice University, Houston, TX.

\section{About the authors}

Duc Hoan Tran received the MSc in Electrical Engineering from Institut National Polytechnique de Toulouse. He is currently working toward the PhD Degree at the LAPLACE laboratory.

Bruno Sareni is Associate Professor in Electrical Engineering and Control Systems at the Institut National Polytechnique de Toulouse. He is also a Researcher at the LAPLACE laboratory. His research activities are related to the integrated optimal design of electrical systems using artificial evolution algorithms. Bruno Sareni is the corresponding author and can be contacted at: sareni@laplace.univ-tlse.fr

Xavier Roboam is a CNRS full-time researcher at LAPLACE laboratory (Institut National Polytechnique de Toulouse). Since 1998, he has been the Head of the team "GENESYS" whose objective is to develop design methodologies specifically oriented toward multi-field systems design for applications such as electrical embedded systems and renewable energy systems.

Eric Bru obtained the MSc degree in Electrical Engineering from IE CNAM in 2005. He joined the LAPLACE Laboratory as a Test Engineer in 2006. He develops, in the GENESYS-Team, test benches devoted to HVDC networks and renewable energy systems.

André De Andrade received the MSc Degree in Electrical Engineering from the Institut National Polytechnique de Toulouse in 2007. He is currently working toward the $\mathrm{PhD}$ Degree at the LAPLACE laboratory. 